\title{
The plasma membrane calcium pump in the hearing process: physiology and pathology
}

\author{
Ernesto CARAFOLI \\ Venetian Institute of Molecular Medicine, University of Padova, Padova 35121, Italy
}

Received June 11, 2011; accepted June 22, 2011

\begin{abstract}
Mammalian cells express four different plasma membrane $\mathrm{Ca}^{2+}$ ATPases. Two of them (PMCA1 and PMCA4) are expressed ubiquitously, and are considered housekeeping isoforms. Two (PMCA2 and PMCA4) have tissue restricted distribution. They are abundantly expressed in the brain and in nervous tissue-derived cell types. The primary transcripts of all PMCAs undergo alternative splicing, generating a large number of additional isoforms. Splicing occurs at site A, in the N-terminal moiety of the pump, and at site $\mathrm{C}$, within the $\mathrm{C}$-terminal calmodulin binding domain: The pumps are canonical targets of calmodulin stimulation. The site $\mathrm{C}$ insertion leads to a truncation of the pump about 50 residues short of the original C-terminal. One of the pumps (PMCA2) has special properties: It displays high activity even in the absence of the natural activator calmodulin, and has a particularly complex pattern of alternative splicing at both sites A and C. A variant of the PMCA2 pump containing an insert at site A and truncated C-terminally is the resident isoform of the pump in the stereocilia of hair cells of the inner ear. It exports $\mathrm{Ca}^{2+}$ to the endolymph that bathes the stereocilia less efficiently than the full length, non-inserted PMCA2 pump. The proper functioning of hair cells demands the precise maintenance of the $\mathrm{Ca}^{2+}$ balance between hair cells and the endolymph. Disturbances in the balance affect the process of mechano-electrical transduction, which depends on the ability of the stereociliar bundle to deflect in response to sound waves. The tip links that organize the bundle are formed by the $\mathrm{Ca}^{2+}$ binding protein cadherin 23 and by protocadherin 15: Disturbances of the $\mathrm{Ca}^{2+}$ binding by cadherin 23 and/or of the ability of the PMCA2 variant of the stereocilia to export $\mathrm{Ca}^{2+}$ to the endolymph generate hearing loss phenotypes. Such phenotypes have now been described in mice and humans. In some cases they are linked to mutations of both cadherin 23 and the PMCA2 pump, but in other cases they may be generated by mutations of particular severity in only one of the two proteins. The PMCA2 defect that leads to deafness has now been analyzed molecularly: It affects the long range, unstimulated ability of PMCA2 to export $\mathrm{Ca}^{2+}$.
\end{abstract}

calcium ATPases, PMCA2, hereditary deafness, calmodulin, hair cells

Citation: Carafoli E. The plasma membrane calcium pump in the hearing process: physiology and pathology. Sci China Life Sci, 2011, 54: 686-690, doi: $10.1007 / \mathrm{s} 11427-011-4200-\mathrm{z}$

Separate genes, located in four different chromosomes, code for the four basic isoforms of the plasma membrane calcium ATPase (PMCA pump) in mammals. These ATPases are $134 \mathrm{kD}$ proteins, organized in the plasma membrane with 10 transmembrane domains and a long C-terminal tail that contains a calmodulin binding domain. The primary transcript of each one of the four basic isoforms undergoes al-

email: ernesto.carafoli@unipd.it ternative splicing, increasing the number of PMCA pump variants to over 30 [1]. Two of the four basic gene products are distributed ubiquitously in mammalian tissues (PMCA1 and PMCA4): They are thus considered as housekeeping isoforms (however, PMCA4 could also have a specific role in some cell types, e.g., the spermatozoa [2]). PMCA2 and PMCA3 are expressed in a much more limited range of tissues, such as the nervous system. Alternative splicing occurs at two sites in the pump structure: Site A is located in 
the cytosolic loop that connects transmembrane domains 2 and 3, site $\mathrm{C}$ within the $\mathrm{C}$-terminal calmodulin binding domain. The insert(s) at site $\mathrm{A}$ are in frame, those at site $\mathrm{C}$ are not, and generate a premature stop codon that truncates the pump some 50 residues short of the original C-terminal. The PMCA pump is a classical target of calmodulin stimulation: Its canonical C-terminal calmodulin binding domain folds over in the resting state to bind to the two first cytosolic loops $[3,4]$, maintaining the pump in an auto-inhibited state which is relieved by the binding of calmodulin to its domain. The stimulation of the activity of the pump has been studied in detail using isoforms 1 and 4, which were the first to be purified [5]. Calmodulin decreases the $\mathrm{Ca}^{2+} K_{\mathrm{m}}$ of the pump from 5-10 to about $0.5 \mu \mathrm{mol} \mathrm{L}{ }^{-1}$, and raises its $V_{\max } 5$ or 6 folds. Its binding affinity $\left(K_{\mathrm{d}}\right)$ for the pump is highest in PMCA2 (2-4 nmol L $\left.{ }^{-1}\right)$ intermediate in PMCA3 (8 nmol $\left.\mathrm{L}^{-1}\right)$ and lowest in PMCA1 and 4 (30-50 nmol L $\left.{ }^{-1}\right)$ [1].

The splicing operation inserts a single exon (36-42 bp) at site $\mathrm{A}$ in isoforms 1, 2, and 3, and up to 3 exons in PMCA2. According to the most widely used nomenclature, the pump variant without site $\mathrm{A}$ inserts is designated as variant $z$, that with one insert as variant $x$, that with two inserts as variant $y$, and that with three inserts as variant $w$ : Variants $y$ and $w$ only concern PMCA2 [1]. At site $\mathrm{C}$ the splicing operation inserts one exon in the transcript of PMCA1, PMCA4, and PMCA3. The insertion occurs piecemeal, leading to tvariant $a$ when the full exon is inserted, and to variant $b$ when no insertion occurs. In the case of PMCA2, splicing at site $\mathrm{C}$ includes or excludes two, not one, novel exons: As in the other isoforms, the PMCA2 variant without site $\mathrm{C}$ inserts is designated as $b$, that with both exons (172 and $55 \mathrm{bp}$, respectively) inserted as $a$ [1]. As mentioned, the site $C$ insertions are not in frame, and generate truncated forms of the pump. Not much is known on the functional activity of the spliced pump variants; however, as could be predicted by the truncation of the calmodulin binding domain, the $a$ variants have decreased affinity for calmodulin.

\section{The PMCA2 pump}

The unique complexity of the splicing operation in PMCA2 is not the only property that sets this isoform apart from the other three. Studies on the sensitivity to calmodulin show that PMCA2 has peculiarly high activity in its absence [6,7]. Table 1 shows that calmodulin stimulates the activity of PMCA4 at saturating $\mathrm{Ca}^{2+} 4-5$ folds, but that of PMCA2 only about $1.3-1.4$ folds. PMCA2 is thus able to efficiently pump $\mathrm{Ca}^{2+}$ even in the absence of the natural activator calmodulin. In the cell environment, its $\mathrm{Ca}^{2+}$ exporting activity will thus be somehow protected from variations in the concentration of the activator in its vicinity. The reasons for the peculiarly high activity of PMCA2 in the absence of calmodulin are still obscure.In spite of the very high affinity for calmodulin, no tightly bound activator was found in purified PMCA2 preparations. Possibly, the interaction of the C-terminal calmodulin binding domain of PMCA 2 with the auto-inhibitory sites close to the active site of the enzyme would be less efficient than in the other three isoforms, making PMCA2 constitutively active.

As mentioned, PMCA2 is abundantly expressed in the nervous tissue. Most brain regions express large amounts of it, as do cells of nervous derivation, such as the hair cells of the Corti Organ of the inner ear. Hair cells are characterized by stereocilia that protrude into the endolymph, an extracellular fluid that has a peculiarly low $\mathrm{Ca}^{2+}$ concentration $\left(\sim 20 \mu \mathrm{mol} \mathrm{L}{ }^{-1}\right)$. PMCA2 is highly concentrated in the stereociliar plasma membrane, and exports $\mathrm{Ca}^{2+}$ to it. Evidently, the special properties of PMCA2 have been selected to satisfy the $\mathrm{Ca}^{2+}$ homeostasis requirements of a fluid as special as the endolymph. However, the properties of the normal $z b$ variant of PMCA2 were perhaps not completely adequate for the $\mathrm{Ca}^{2+}$ homeostasis requirements of the endolymph: The resident pump of the stereocilia is thus the $w a$ truncated variant of PMCA2 [8], which has lower $\mathrm{Ca}^{2+}$ exporting activity than the non-inserted full length $z b$ variant: The experiment shown in Figure 1, which records the activity of the pumps in the cell environment, shows clearly that the truncated form of PMCA2 has lower $\mathrm{Ca}^{2+}$ exporting ability than the full length, non-spliced variant.

Table 1 Calmodulin stimulation of PMCA2 and PMCA4 ${ }^{\text {a) }}$

\begin{tabular}{ccc}
\hline & \multicolumn{2}{c}{$\begin{array}{c}\mathrm{Ca}^{2+} \text {-dependent ATPase activity } \\
\left(\mathrm{nmol} \text { ATP } \mathrm{mg}_{\text {protein }}{ }^{-1} \mathrm{~min}^{-1}\right)\end{array}$} \\
\cline { 2 - 3 } & -Calmodulin & +Calmodulin \\
\hline PMCA2 & 4.21 & 5.87 \\
PMCA4 & 1.45 & 6.15 \\
\hline
\end{tabular}

a) From [6] and [7].

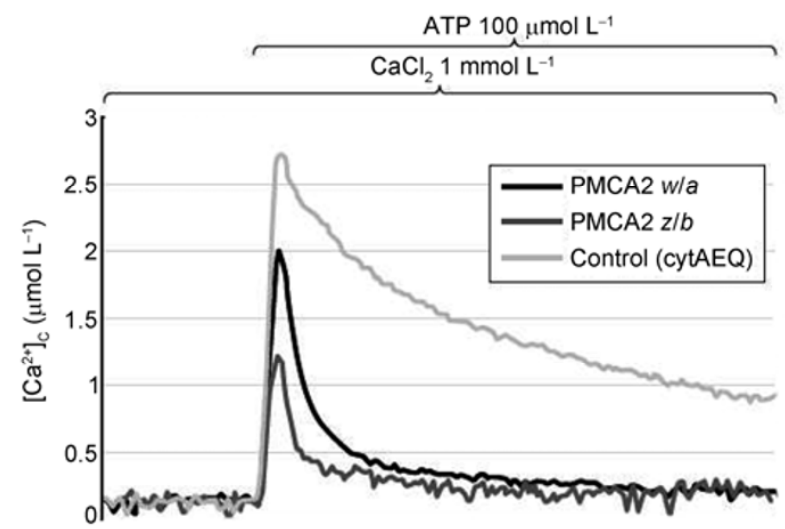

Figure 1 Monitoring of cytosolic $\mathrm{Ca}^{2+}$ concentration $\left[\mathrm{Ca}^{2+}\right]_{\mathrm{c}}$ in $\mathrm{CHO}$ cells transfected with the $\mathrm{Ca}^{2+}$ sensitive recombinant protein aequorin (cytAEQ) and splice variants $z b$ and $w a$ of the PMCA2 pump. The $\mathrm{Ca}^{2+}$ transient was induced by ATP, a purinergic agonist that liberates inositol-tris-phosphate [1]. Full details on the technical details of the experiment are found in [15]. 
Interest in the presence and function of PMCA2 in the hair cells of the inner ear was heightened by the analysis of the phenotype of PMCA2 knock out mice [9], which was characterized by balance disturbance and hearing loss. The study of the vestibular inner hear revealed the absence of the otoconia and the progressive degeneration of the hair cells beginning 10 days after birth. At about the same time, the first spontaneous mice mutation of the PMCA 2 pump was described (the deafwaddler G283S mutation [10]), which had equilibrium defects and a deafness phenotype. Another spontaneous PMCA2 pump mutation that produced equilibrium imbalance and hearing loss (the Wriggle Sagami mouse [11]) was described shortly afterwards: A $\mathrm{K} 412 \mathrm{E}$ replacement in the fourth transmembrane domain of the pump prevented its correct targeting to the plasma membrane of the stereocilia. Following these initial findings, the involvement of PMCA2 in the hearing process became a topic of intensive studies. It has now led to a better understanding of the role of $\mathrm{Ca}^{2+}$ in the physiology of the hair cells of the inner ear, and of the fine properties of PMCA2 in the homeostasis of $\mathrm{Ca}^{2+}$ in hair cells and the endolymph.

\section{Calcium in the hearing process}

Hearing depends on the ability of the inner ear to convert the sound waves transmitted through the endolymph into signals that are transduced by the hair cells of the Corti organ through the mechanoelectric transduction (MET) process. The outer hair cells do not send signals to the acoustic area of the brain: They act as mechanosensors that amplify the mechanical vibrations of the basilar membrane in response to sound. The amplification activates the MET process in the inner hair cells that release neurotransmitters to afferent dendrites of neurons in the spiral ganglion triggering action potentials that relay acoustic signals to the brain. As mentioned, the endolymph bathes the stereociliar bundle of the hair cells, deflecting them in response to sound waves to induce the opening of stereocilia channels that mediate the penetration of $\mathrm{K}^{+}$and $\mathrm{Ca}^{2+}$ into the stereociliar cytoplasm. Recent work performed under the $\mathrm{Ca}^{2+}$ concentration conditions of the endolymph [12] has shown that only about $0.2 \%$ of the total MET current is carried by $\mathrm{Ca}^{2+}$. The very low $\mathrm{Ca}^{2+}$ concentration of the endolymph must be very precisely controlled, as $\mathrm{Ca}^{2+}$ binds reversibly to $\mathrm{EF}$ hand motifs of cadherin 23, a single pass transmembrane protein that protrudes into the endolymph to form, together with protocadherin 15, the tip links that organize the stereociliar bundle to promote their deflection. $\mathrm{Ca}^{2+}$ that enters the stereociliar cytoplasm through the MET channels would have to be continuously exported back to the endolymph by the doubly spliced truncated wa variant of PMCA2. Cadherin 23 and the PMCA2 wa variant are thus two of the components which are essential to the correct functioning of the
MET process of hair cells. Alterations of the $\mathrm{Ca}^{2+}$ homeostasis of the endolymph, and/or the impairment of the ability of cadherin 23 to properly bind $\mathrm{Ca}^{2+}$, would disrupt the MET process, generating a sensorineural deafness phenotype.

\section{PMCA2 pump defects and hereditary deaf- ness}

The deafness phenotype in PMCA2 knockout mice and in mice carrying the G283S mutation of PMCA2 has already been mentioned, but cadherin 23 mutations, as expected, can also produce a deafness phenotype [13]. Interest in the phenotypes of hereditary deafness linked to disturbances of hair cell $\mathrm{Ca}^{2+}$ homeostasis has now grown considerably. Such phenotypes have been described in mice and humans [10,14-17], and are frequently produced by the combined mutations of both proteins. However, it could be expected that defects of only one of the two proteins, if particularly severe, would be sufficient to generate the deafness phenotype: Indeed, mutations in the PMCA that induce deafness per se, i.e., without concomitant mutations of cadherin 23 have been described in mice [16,17]. In turn, a human family has been described in which the deafness phenotype was induced by the cadherin 23 mutation, and was only exacerbated by a concomitant mutation in the PMCA pump [14]. Another human case [15] was of particular interest, since one of the parent had a PMCA2 mutation, and the other the cadherin 23 mutation. They were both healthy, but the deafness phenotype became manifest in a son who carried both mutations: a classical digenic mechanism. Figure 2 summarizes the mutations of PMCA 2 that have so far found to induce deafness in mice and humans, and indicates the loci of the mutations in the pump molecule.

The PMCA2 pump defect has so far only been analyzed molecularly in three mice and one human case [15-17] (Figures 3-5). Based on the type of amino acid substitution, defects of different severity could have been expected: For instance, the G293S mutation of the human case described by Ficarella et al. [15] was located in a portion of the pump molecule which was distant from any functionally sensitive sites. Its effect on the $\mathrm{Ca}^{2+}$ exporting function of the pump was thus relatively minor (Figure 3 ). By contrast, in the Oblivion and Tommy mice (Figures 4 and 5) the mutations affected a residue located in the immediate vicinity of the active site of the pump, or within one of the transmembrane domains: The function of the pump was thus more severely affected. Qualitatively, however, the basic defect in all mutations followed the same pattern: The mutated PMCA 2 wa pumps expressed in model cells had decreased ability to export $\mathrm{Ca}^{2+}$ out of the cell. However, as Figures 3-5 show, the defect was not so much in the ability of the mutated pumps to immediately control the arrival of a large $\mathrm{Ca}^{2+}$ pool, but in the ability to efficiently return the $\mathrm{Ca}^{2+}$ level to 


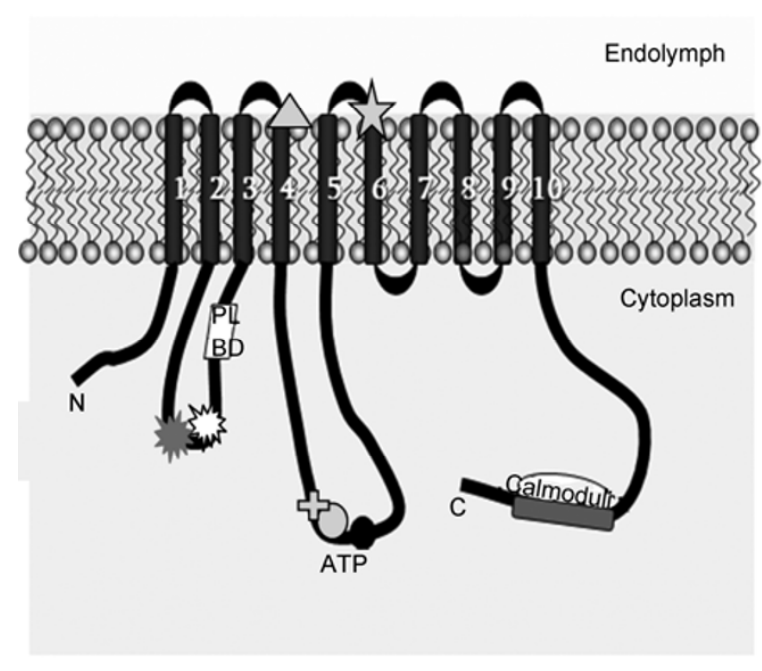

Knock out mice: Mice are deaf and present vestibular /motor imbalance. Abnormalities of the organ of Corti are also present [9].

Deafwaddler mice: G283S. Mice are deaf and present vestibular/motorimbalance [10].

Wriggle Sagami Mouse (E412K). The level of PMCA2 expression may be reduced and mice present hearing loss [11].

Tommy (E584K): Mice are deaf and present ataxia [17].

Oblivion (S877F): Mice present ataxia, loss of balance and progressive loss of auditory function [16].

Human mutation V586M increases the severity of hearing loss in a deafness family with a mutation in the cdh23 [14].

Human mutation (G293S) creates hearing loss by a digenic mechanism involving the cadherin 23 gene in a human family [15].

Figure 2 A summary of the deafness-inducing PMCA2 pump mutations in which the functional defect of the pump has been documented. The figure also shows the locations of the mutations in the pump molecule.

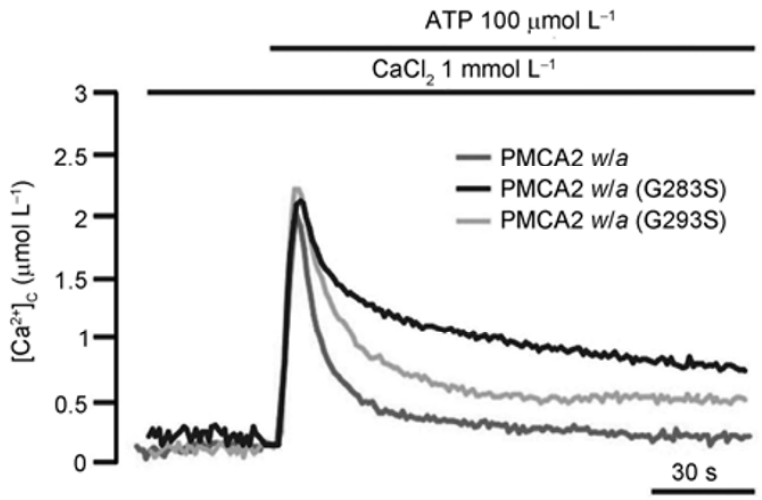

Figure 3 Experimental conditions as in Figure 1, except that the $\mathrm{CHO}$ cells were transfected with the PMCA2 pump mutants deafwaddler (G283S) and G293S.

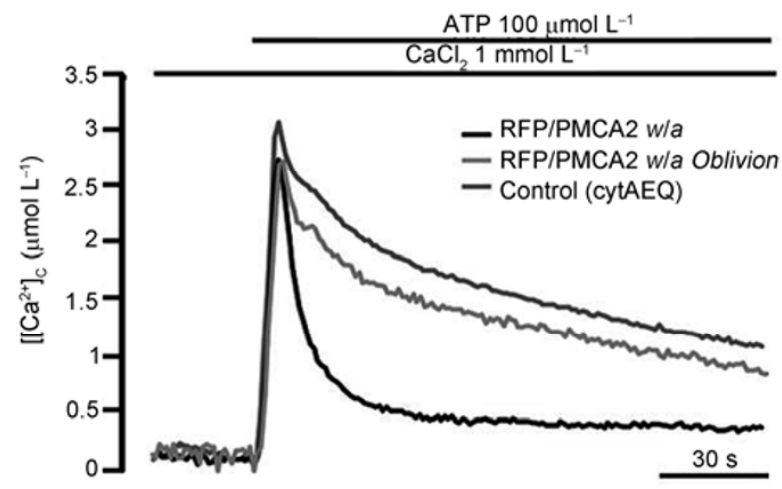

Figure 4 Experimental conditions as in Figure 1. The $\mathrm{CHO}$ cells were transfected with the PMCA2 Oblivion mutant (S877F).

the baseline after the transient, i.e., in the long range ability to continuously eject $\mathrm{Ca}^{2+}$. When translated to the hair cell-stereocilia situation, these findings would correspond to

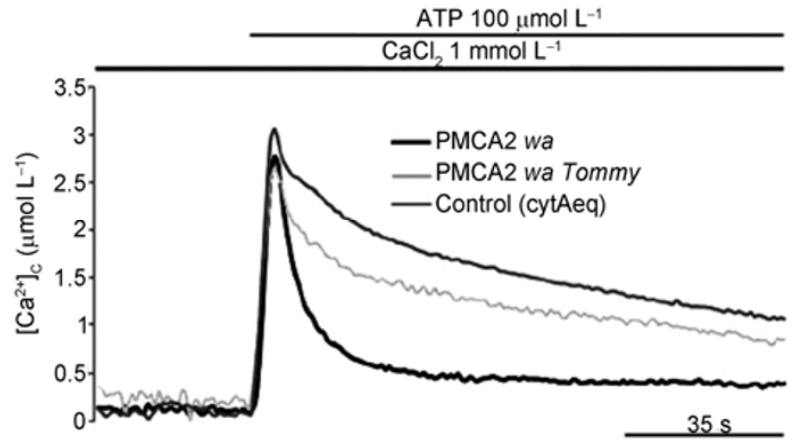

Figure 5 Experimental conditions as in Figure 1. The CHO cells were transfected with the PMCA2 pump mutant Tommy (E584K).

the continuously impaired return of the $\mathrm{Ca}^{2+}$ that had entered through the MET channels $\mathrm{Ca}^{2+}$ to the endolymph. The expected result of the defect would conceivably be the alteration of the homeostasis of $\mathrm{Ca}^{2+}$ in the endolymph, with the consequent impairment of the function of the cadherin 23/ protocadherin 15 tip links.

\section{Concluding remarks}

The cases of hereditary deafness linked to PMCA2 defects are rare, at least when the pump is the only actor affected. However, the importance of maintaining the correct $\mathrm{Ca}^{2+}$ homeostasis in the endolymph, which is a task of the PMCA2 pump, and of the correct concerted functioning of PMCA2 and cadherin 23 extend greatly the possible consequences of the malfunction of the pump, i.e., the pump defects could act as modifiers of a much larger range of hearing loss phenotypes, genetic and/or environmental, linked to pathological processes affecting hair cells. 
1 Brini M, Carafoli E. Calcium pumps in health and disease. Physiol Revs, 2009, 89: 1341-1378

2 Okunade G W, Miller M L, Pyne G I, et al. Targeted ablation of plasma membrane $\mathrm{Ca}^{2+}$ ATPase (PMCA) 1 and 4 indicates a major housekeeping function for PMCA1 and a critical role in hyperactivated sperm motility and male fertility for PMCA4. J Biol Chem, 2004, 279: 33742-33450

3 Falchetto R, Vorherr T, Brunner J, et al. The plasma membrane $\mathrm{Ca}^{2+}$ pump contains a site that interacts with its calmodulin binding domain. J Biol Chem, 1991, 266: 2930-2936

4 Falchetto R, Vorherr T, Carafoli E. The calmodulin binding site of the plasma membrane $\mathrm{Ca}^{2+}$ pump interacts with the transduction domain of the enzyme. Protein Sci, 1992, 1: 1613-1621

5 Niggli V, Penniston J T, Carafoli E. Purification of the $\left(\mathrm{Ca}^{2+}-\mathrm{Mg}^{2+}\right)$ ATPase from human erythrocyte membranes using a calmodulin affinity column. J Biol Chem, 1979, 254: 9955-9958

6 Elwess N I, Filoteo A G, Enyedi A, et al. Plasma membrane $\mathrm{Ca}^{2+}$ isoforms $2 \mathrm{a}$ and $2 \mathrm{~b}$ are unusually responsive to calmodulin and $\mathrm{Ca}^{2+}$. J Biol Chem, 1997, 292: 17981-17986

7 Hilfiker H, Guerini D, Carafoli E. Cloning and expression of isoform 2 of the plasma membrane $\mathrm{Ca}^{2+}$ ATPase. Functional properties of the enzyme and of its splicing products. J Biol Chem, 1994, 269: 26178-26183

8 Grati M, Aggarval N, Strehler E S, et al. Molecular determinants for differential membrane trafficking of PMCA1 and PMCA2 in mammalian hair cells. J Cell Sci, 2006, 119: 2995-3007

9 Kozel P J, Friedman R A, Erway L C, et al. Balance and hearing def- icits in mice with a null mutation in the gene encoding plasma membrane $\mathrm{Ca}^{2+}$ ATPase isoform 2. J Biol Chem, 1998, 273: 18693-18696

10 Street V A, McKee-Johnson J W, Fonseca R C, et al. Mutations in a plasma membrane $\mathrm{Ca}^{2+}$ ATPase gene cause deafness in deafwaddler mice. Nature Genet, 1998, 19: 390-394

11 Takahashi K, Kitamura K. A point mutation in a plasma membrane $\mathrm{Ca}^{2+}$ ATPase gene causes deafness in Wriggle Mouse Sagami. Biochem Biophys Res Commun, 1999, 261: 773-778

12 Beurg M, Nam J H, Chen Q, et al. Calcium balance and mechanotransduction in rat cochlear-hair cells. J Neurophysiol, 2010, 104: $18-34$

13 Sotomayor M, Weilhofen W A, Gaudet R, et al. Structural determinants of cadherin-23 function in hearing and deafness. Neuron, 2010, 66: 85-100

14 Schultz J M, Yang J, Caride A J, et al. Modification of human hearing loss by plasma membrane calcium pump PMCA 2. N Engl J Med, 2005, 352: 1557-1664

15 Ficarella R, Di Leva F, Bortolozzi M, et al. A functional study of plasma membrane calcium pump isoform 2 mutants causing digenic deafness. Proc Natl Acad Sci USA, 2007, 104: 1516-1521

16 Spiden S L, Bortolozzi M, Di Leva F, et al. The novel mouse mutation Oblivion inactivates the PMCA 2 pump and causes progressive hearing loss. PLoS Genet, 2008, 4: e1000238

17 Bortolozzi M, Brini M, Parkinson N, et al. The novel PMCA2 pump mutation Tommy impairs cytosolic calcium clearance in hair cells and links to deafness in mice. J Biol Chem, 2010, 285: 3769337703

Open Access This article is distributed under the terms of the Creative Commons Attribution License which permits any use, distribution, and reproduction in any medium, provided the original author(s) and source are credited. 